Communication

\title{
Exploration of Mechanochemical Activation in Solid-State Fluoro-Grignard Reactions
}

\author{
Isaiah R. Speight $(\mathbb{D}$ and Timothy P. Hanusa *(D) \\ Department of Chemistry, Vanderbilt University, Nashville, TN 37235, USA; isaiah.r.speight@vanderbilt.edu \\ * Correspondence: t.hanusa@vanderbilt.edu; Tel.: +1-615-322-4667
}

Academic Editors: Vjekoslav Štrukil and Matej Baláž

Received: 30 November 2019; Accepted: 27 January 2020; Published: 28 January 2020

check for updates

\begin{abstract}
Owing to the strength of the C-F bond, the 'direct' preparation of Grignard reagents, i.e., the interaction of elemental magnesium with an organic halide, typically in an ethereal solvent, fails for bulk magnesium and organofluorine compounds. Previously described mechanochemical methods for preparing Grignard reagents have involved ball milling powdered magnesium with organochlorines or bromines. Activation of the $\mathrm{C}-\mathrm{F}$ bond through a similar route is also possible, however. For example, milling 1- and 2-fluoronaphthalene with an excess of magnesium metal for $2 \mathrm{~h}$, followed by treatment with $\mathrm{FeCl}_{3}$ and additional milling, produces the corresponding binaphthalenes, albeit in low yields (ca. 20\%). The yields are independent of the particular isomer involved and are also comparable to the yields from corresponding the bromonaphthalenes. These results may reflect similar charges that reside on the $\alpha$-carbon in the naphthalenes, as indicated by density functional theory calculations.
\end{abstract}

Keywords: mechanochemistry; organic chemistry; organofluorine; Grignard reaction; ball milling

\section{Introduction}

For well over a century, the indispensable Grignard reagents have played critical roles in the synthetic chemist's toolbox, and the range of reactions they facilitate is enormous [1-3]. Various methods have been used to promote the so-called 'direct' preparation of Grignard reagents, i.e., the interaction of elemental magnesium with an organic halide, usually in an ethereal solvent [4]. The application of ultrasound [5,6] or microwave irradiation [7], and the formation of finely divided metal powders, have all been used to boost the reactivity of elemental magnesium. Exploration of the latter approach was pioneered by Rieke, who prepared highly reactive metals by reducing metal salts with alkali metals or organoalkalis in ethereal or hydrocarbon media [8-14]. Peripherally related to this technique, in that exceptionally small metal particles are involved, is mechanochemical activation of reactions, typically achieved through grinding or ball milling. The process provides energy input without requiring the use of solvents or the application of elevated temperatures [15-20]. Although the literature on the subject is not large, mechanochemical methods have been employed in Grignard chemistry with various degrees of success.

Mechanochemical approaches have sometimes involved the use of preformed Grignard reagents [21], and Mack determined that as long as the grinding vessel was sealed, the milling of Grignard reagents and substrates need not be performed in rigorously anhydrous or anerobic environments [22]. The actual generation and subsequent use of Grignard reagents under mechanochemical conditions has been studied in the context of dehalogenation reactions. Complete dechlorination of 1,3,5-trichlorobenzene, for example, is achieved when it is milled with magnesium and $n$-butyl amine. The process involves the stepwise formation of the corresponding Grignard reagents, for which the amine serves as a hydrogen donor, ultimately generating benzene [23]; other organochlorines have been similarly investigated [24,25]. 
In the search for more general synthetic applications, Harrowfield reported the solvent-free reaction of magnesium with halogenonaphthalenes in a ball mill [26]. The use of at least a four-fold excess of magnesium was required to produce a manipulable solid, instead of an intractable paste. Not surprisingly, the presence of the highly reactive excess magnesium powder complicated further reactions. When quenched with aromatic ketones, for example, McMurry coupling occurred in addition to the alcohol formation expected from reaction with the organomagnesium species (Scheme 1).

2
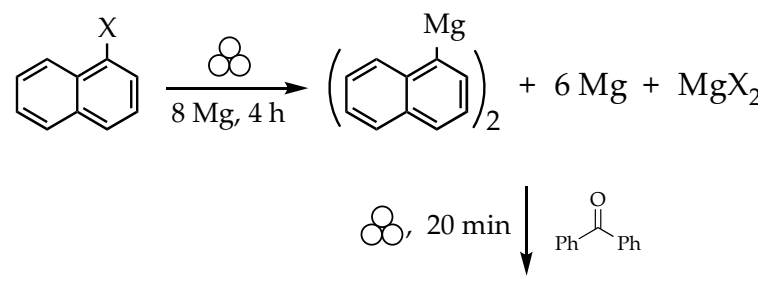

Scheme 1. Products of the milling of magnesium $(\mathrm{Mg})$ with halogenonaphthalenes $(\mathrm{X}=\mathrm{Cl}, \mathrm{Br})$ [26]. The tertiary alcohol is the expected product from the Grignard reagent; the diol and alkene are consequences of McMurry coupling from the large amount of finely divided $\mathrm{Mg}$ in the reaction. This scheme follows the proposal of Kaupp [27], who suggested that the organomagnesium intermediate operative in this system is likely di(napthyl)magnesium, rather than a napthylmagnesium halide. The symbol for mechanochemical reaction conditions is adopted from ref. [16].

Despite the somewhat uncertain prospects for the clean mechanochemical generation of an $\mathrm{RMgX}$ species, we were interested in investigating Grignard systems that do not usually work well-if at all-in solution, specifically fluoro-Grignards (' $\mathrm{RMgF}^{\prime}$ ). The C-F bond is roughly $38 \mathrm{kcal} \mathrm{mol}^{-1}$ stronger than the next strongest carbon-halogen bond $(\mathrm{C}-\mathrm{Cl})$ [28], and the attempted reaction of elemental magnesium with an organofluorine in solution is usually unsuccessful [29]. Exploration of this issue dates back a century, beginning with the work of Swarts in 1921 [30], and an array of methods has been used in efforts to provide a more reactive magnesium source [31]; some of the early strategies have been reviewed [32].

It should be noted that the preparation of fluoro-Grignard reagents has been described via indirect routes from organomagnesium compounds, including other Grignard reagents [33]. For example, the reaction of EtMgBr with perfluoraryl compounds in the presence of certain transition metal halide catalysts (e.g., $\mathrm{CoCl}_{2}, \mathrm{NiCl}_{2}$, and $\mathrm{CuI}$ ) was used to generate the corresponding ArMgF species that then underwent the expected Grignard reactions [34]. Similarly, the reaction of $\mathrm{MgR}_{2}(\mathrm{R}=\mathrm{Me}, \mathrm{Et}, \mathrm{Bu}$, and $\mathrm{Ph}$ ) with fluorinating agents such as $\mathrm{BF}_{3} \cdot \mathrm{OEt}_{2}, \mathrm{Bu}_{3} \mathrm{SnF}$, and $\mathrm{SiF}_{4}$ produced the associated $\mathrm{RMgF}$ species, although not always in high purity [32]. Crabtree reported the use of the thermally sensitive magnesium anthracene $\left(\mathrm{MgC}_{14} \mathrm{H}_{10}\right)$ to activate perfluorinated alkyl or aryl compounds, followed by reaction with $\mathrm{CO}_{2}$ to produce carboxylic acids, albeit in low to moderate yields (6-34\%). Reaction of the same organofluorines with elemental magnesium yielded no product, nor did the reaction of perfluoronapthalene with $\left(\mathrm{MgC}_{14} \mathrm{H}_{10}\right)$ [35].

Despite these reports, the lure of a direct route to fluoro-Grignards remains, as it would avoid the need for prior synthesis of an organomagnesium reagent that might not be readily accessible, and hence the potential range of $\mathrm{R}$ groups could be larger. Rieke's first work with finely divided magnesium (Mg) focused on organochlorines and -bromines, but fluorobenzene was examined as well [8]. The refluxing of fluorobenzene with $\mathrm{Mg}$ in diglyme for $1 \mathrm{~h}$, followed with treatment with $\mathrm{CO}_{2}$, produced benzoic acid in very low yield (ca. 5\%) [36,37]. Evidence for the formation of fluoro-Grignards by these bulk synthetic methods is indirect, e.g., the formation of the expected reaction products (e.g., after hydrolysis or treatment with $\mathrm{CO}_{2}$ ), which is consistent the formation of $\mathrm{RMgF}$ species 
as intermediates. For the sake of completeness, it could be mentioned that magnesium vapor has been used to prepare fluoro-Grignards at low temperatures. For example, when excited state $\left({ }^{3} \mathrm{P}\right)$ magnesium atoms produced from laser ablation experiments were allowed to react with methyl halides diluted in an argon matrix, Grignard molecules $\mathrm{CH}_{3} \mathrm{MgX}$, including the fluoride species, $\mathrm{CH}_{3} \mathrm{MgF}$, were identified [38]. Similarly, cluster Grignard reagents $\left(\mathrm{C}_{6} \mathrm{H}_{5} \mathrm{Mg}_{\mathrm{n}} \mathrm{X}\right)$, including the combination $n=4, \mathrm{X}=\mathrm{F}$, have been produced by metal vapor synthesis [39,40]. Finally, although it does not involve the reaction of organometallic compounds, it might be noted that the reaction of (BDI)Mg-Mg(BDI) $\left(B D I=\kappa^{2}-\left\{2,6-{ }^{i} \operatorname{Pr}_{2} \mathrm{C}_{6} \mathrm{H}_{3} \mathrm{NCMe}\right\}_{2} \mathrm{CH}\right)[41,42]$ with a series of perfluorinated and polyfluorinated arenes generates (BDI)MgF by a process deemed 'equivalent' to Grignard formation in solution [43].

We report here the use of the mechanochemical activation of $\mathrm{Mg}$ with fluorinated naphthalenes, in which it is clear that $\mathrm{C}-\mathrm{F}$ bond activation has occurred, although there are still practical issues that must be overcome prior to more general development of the method. There have been cautions raised about the potentially explosive nature of fluorinated Grignards [29], but no such difficulties were encountered with the monofluoro organics used here.

\section{Results and Discussion}

\subsection{Exploration of Mechanochemically Generated Grignard Reagents}

Owing to the paucity of literature on mechanochemically driven Grignard chemistry, and to the potential sensitivity of reaction outcomes to the specific equipment and conditions employed, we selected several homocoupling reactions as calibration points for reactivity. In these cases, there are no other potential organic products other than ones generated from the Grignard reagents themselves. For this initial study, aromatic substrates were chosen as more likely to provide greater reactivity than the saturated equivalents [35]. A coupling reagent whose efficacy has been established in solution chemistry $\left(\mathrm{FeCl}_{3}\right)$ was chosen [44,45], and bromobenzene was used as the substrate. As noted above, Harrowfield found that a considerable excess (at least $4 \times$ stoichiometric levels) of magnesium metal was required when milling it in Grignard reactions [26]. The use of smaller amounts led to pasty mixtures that could not be easily manipulated. We found a similar situation to be true, but perhaps because of our use of finer $\mathrm{Mg}$ powder (325 mesh) than in Harrowfield's experiments (50 mesh), eight equiv. of $\mathrm{Mg}$ were required to produce a friable reaction product. Milling experiments were carried out using $100 \mathrm{mg}$ of $\mathrm{PhBr}$, eight equiv. of $\mathrm{Mg}$, and one equiv. of $\mathrm{FeCl}_{3}$, performed under the conditions stated in Section 3.1. The coupled product biphenyl was generated in reasonably good yield (Equation (1)). It should be noted that biphenyl is a common contaminant in solution reactions involving $\mathrm{PhMgBr}$ [46], but it was not observed under these conditions in the absence of $\mathrm{FeCl}_{3}$.

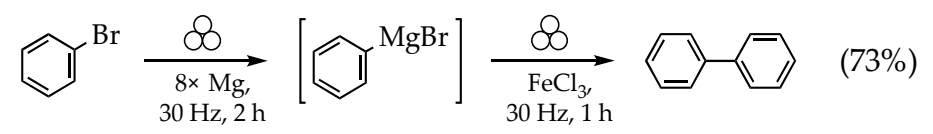

For the initial screening of an organofluorine, 2-fluoronapthalene was selected. Milling it with eight equiv. of $\mathrm{Mg}$ for $2 \mathrm{~h}$ left a black powder that, could be extracted with THF. The extract was then filtered, and the filtrate treated with water, resulting in the production of naphthalene in $79 \%$ isolated yield (Equation (2)); this is similar to the yield of naphthalene reported from milling magnesium with 1-bromo- and 1-chloronapthalene (95\%) [26], although in the latter case the yields were estimated from GC-MS data.

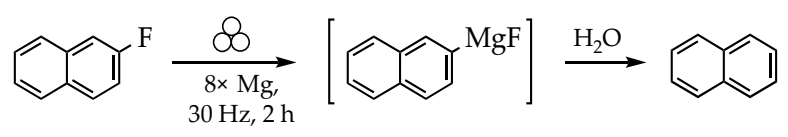


In order to examine more completely the reactivity differences between two sets of halogenated compounds, 1- and 2- bromo- and fluoronaphthalenes were treated with magnesium under the same conditions as used for bromobenzene (Table 1). Regardless of the halide used, the yield of the isolated product binapthalene was almost identical-roughly $20 \%$.

Table 1. Comparison of halide and isomer reactivity in homocoupling reactions with mechanochemically generated Grignard reagents ${ }^{1}$.

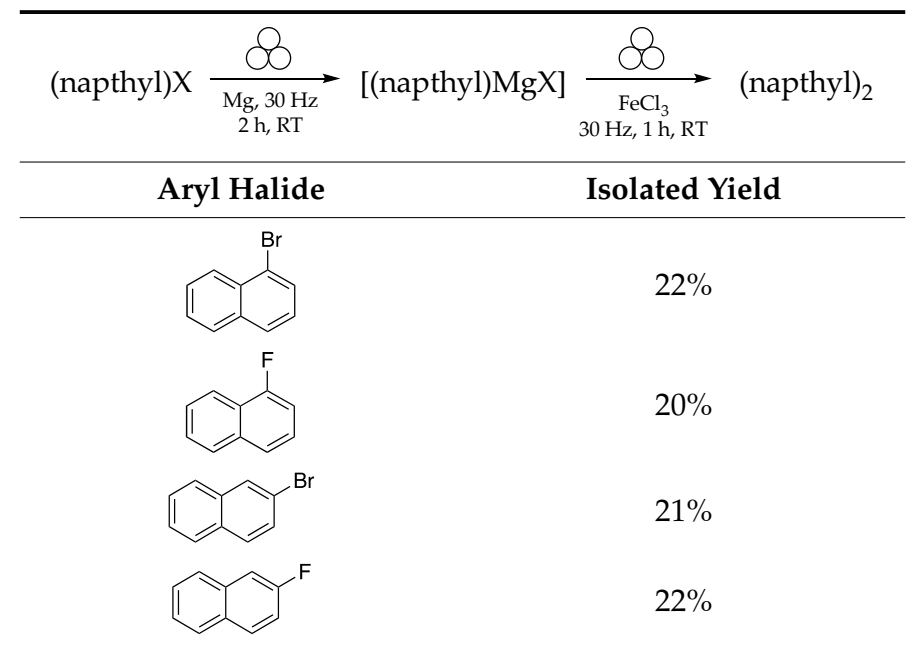

${ }^{1}$ Conditions: halonapthalene (one equiv.), $\mathrm{Mg}$ powder (eight equiv.), $\mathrm{FeCl}_{3}$ (one equiv.), two $8 \mathrm{~mm}$ stainless steel ball bearings ( $\left.3.3 \mathrm{~g} \mathrm{ball}^{-1}\right), \mathrm{N}_{2}$ atmosphere, and isolated yields after column chromatography.

Curiously, and in line with other reports about of the low reactivity of RMgF species towards $\mathrm{CO}_{2}[35,36]$, the presumptive fluoro-Grignards described here were relatively unreactive toward carbonyl addition. Generation of the Grignard reagent was followed by either mechanochemical quenching or treatment of a solution of an electrophile (i.e., benzaldehyde, benzophenone) with the ground powder in order to minimize pinacol and McMurray-type coupling from the excess magnesium powder, yet no product was isolated. Addition of $\mathrm{Et}_{2} \mathrm{O}$ as a liquid-assisted grinding (LAG) agent [47-49] also gave no product formation. The addition of lithium chloride to make a Turbo-Grignard reagent $(\mathrm{RMgX}-\mathrm{LiCl})$ and the addition of Lewis acids, such as $\mathrm{BF}_{3} \cdot \mathrm{OEt}_{2}$, which doubles as an LAG agent, were not successful (see Supplementary Materials). There may be as yet not understood matrix effects that are interfering with subsequent reactivity.

\subsection{Charge Analysis of Grignard Reagents}

Geometry optimization of the (napthyl)MgX and (napthyl) ${ }_{2} \mathrm{Mg}$ compounds was conducted with the dispersion-corrected B3PW91-D3BJ functional and the def2TZVP basis set on all atoms (see Section 3.3 for details). Charge estimation was conducted under the Natural Population Analysis (NPA) protocol (Figure 1). Interestingly, the $\mathrm{Mg}$ atom (or $\mathrm{MgX}$ unit) seems to buffer the charge on the $\alpha$-carbon in each species. In both halonapthalenes, the difference in the carbon change between the fluoro and bromo variants is no more than 0.03 units. Although there is a slightly more negative charge on the $\alpha$-carbons in 2-halonapthalene than in the 1-halo isomer, it does not exceed 0.05 units. The pattern in the (napthyl) ${ }_{2} \mathrm{Mg}$ species is similar, in that the charge on the $\alpha$-carbons in the two complexes differs by no more than 0.04 units. 


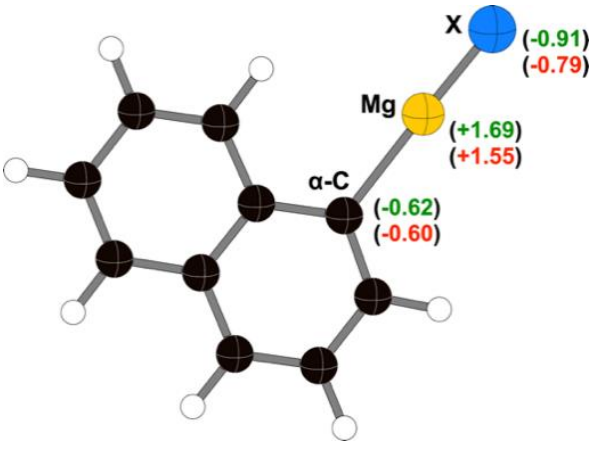

(a)

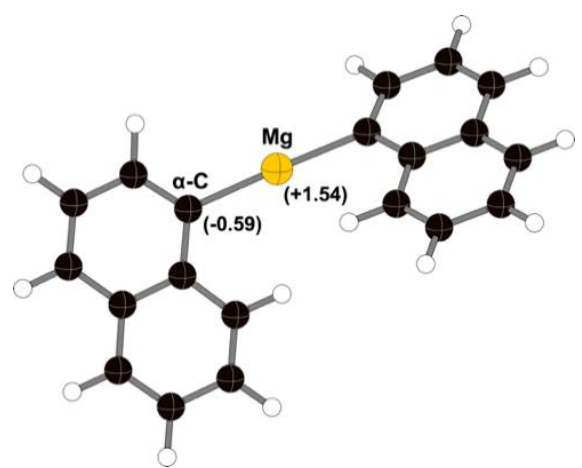

(c)

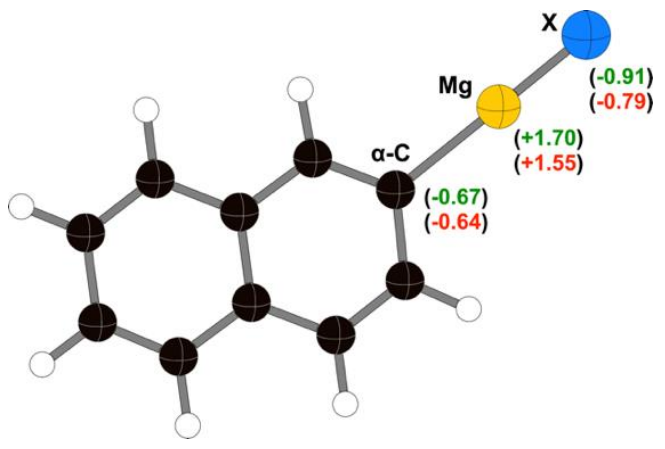

(b)

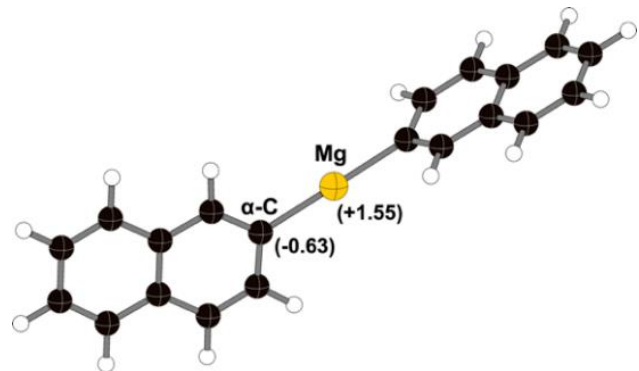

(d)

Figure 1. Natural Population Analysis (NPA) charges on the halogen, $\mathrm{Mg}$, and $\alpha-\mathrm{C}$ in (a) naphthalen-1-ylmagnesium bromide (fluoride); (b) naphthalen-2-ylmagnesium bromide (fluoride); (c) bis(1-napthyl)magnesium; and (d) bis(2-napthyl)magnesium. In (a) and (b), the top values (in green) correspond to the fluoro species, and the bottom values (in red) to the bromo compounds. The (napthyl) ${ }_{2} \mathrm{Mg}$ complexes were optimized under $C_{2}$ symmetry, so the charges on both $\alpha$-carbons in each molecule are the same.

The $\alpha$-carbon charges for all the molecules fall in the range of $-0.63 \pm 0.04$. Accordingly, it should not be surprising that little difference is observed between the reactivity of the fluoro- and bromospecies if, once the bond to $\mathrm{Mg}$ is broken, the nucleophilic carbon is effectively unbiased toward the identity of the halogen that was present prior to activation. It also suggests that it may be difficult to distinguish between a (napthyl) $\mathrm{MgX}$ or a (napthyl) ${ }_{2} \mathrm{Mg}$ species in the coupling reactions.

\section{Materials and Methods}

Unless otherwise noted, all manipulations were performed with the exclusion of air and moisture using Schlenk or glovebox techniques. Bromobenzene (purity $\geq 98 \%$ ), 1-bromonaphthalene (purity $\geq 98 \%$ ), 1-fluoronaphthalene (purity $\geq 98 \%$ ), 2-bromonaphthalene (purity $\geq 98 \%$ ), and 4-fluorotoluene (purity 97\%) were purchased from Oakwood Products, Inc. (Estill, SC, USA), and 2-fluoronaphthalene (purity $\geq 98 \%$ ) was purchased from Fisher Scientific (Pittsburgh, PA, USA). Bromobenzene, 1-bromonaphthalene, 1-fluoronaphthalene, and 4-fluorotoluene were all degassed and stored under a nitrogen atmosphere without further manipulation. Magnesium powder (purity 99\%, $\sim 325$ mesh) was purchased from Strem Chemicals (Newburyport, MA, USA) and stored under a nitrogen atmosphere without further manipulation. Iron(III) chloride was purchased from Sigma-Aldrich (St. Louis, MO, USA), dried under vacuum over an oil bath, and stored under nitrogen. Toluene was degassed with argon and dried over activated alumina, then stored over 4A molecular sieves in a nitrogen atmosphere glovebox. Anhydrous tetrahydrofuran (THF) was stored over 4A molecular sieves in a nitrogen atmosphere glovebox. $\mathrm{CDCl}_{3}$ was obtained from Cambridge Isotopes. 


\subsection{General Procedure for Homocoupling Reactions}

In a typical procedure, a $15 \mathrm{~mL}$ stainless steel Form-Tech milling jar was loaded with two $8 \mathrm{~mm}$ stainless steel (440 grade) ball bearings ( $3.3 \mathrm{~g}$ each). In a nitrogen atmosphere glovebox, the aryl halide (100 mg, one equiv.) and the magnesium powder (eight equiv.) were added to the milling jar. The jar was sealed tightly, and electrical tape was used to protect the atmosphere inside the milling jar. The jar was removed from the glovebox, placed in a Retsch MM 400 mixer mill, and milled for the specified time and frequency $\left(2 \mathrm{~h}, 30 \mathrm{~Hz}\right.$ ). The jar was returned to the glovebox in a c-clamp, and $\mathrm{FeCl}_{3}$ (one equiv.) was added to the ground reaction mixture. The jar was resealed, removed from the glovebox, and remilled $(1 \mathrm{~h}, 30 \mathrm{~Hz})$. Upon being returned to the glovebox, the ground mixture was extracted with toluene (ca. $60 \mathrm{~mL}$ ) and filtered through a medium porosity ground glass frit. After standard workup to isolate the products, the crude materials were purified using column chromatography with hexanes as the eluent. The dried isolated products were identified by their characteristic ${ }^{1} \mathrm{H}-\mathrm{NMR}$ spectra on a Bruker AV-400 spectrometer (Billerica, MA, USA) at $400 \mathrm{MHz}$ [50-52].

\subsection{General Procedure for Quenching Reactions}

The procedure above was followed, but following the initial milling reaction, the material was extracted with THF (ca. $40 \mathrm{~mL}$ ), and the filtrate treated with $15 \mathrm{~mL}$ of deionized water. Workup was as above, but no column purification was used. Products were identified by their characteristic ${ }^{1} \mathrm{H}-\mathrm{NMR}$ spectra on a Bruker AV-400 spectrometer at $400 \mathrm{MHz}$ [53].

\subsection{Procedures for Computational Analysis}

All calculations were performed with the Gaussian 16W suite of programs [54]. The B3PW91 functional, which incorporates Becke's three-parameter exchange functional with the 1991 gradient-corrected correlation functional of Perdew and Wang, was used [55]. To add dispersion correction, Grimme's D3 correction [56] with additional Becke-Johnson damping was used [57] (Gaussian keyword: empiricaldispersion $=$ GD3BJ). The def2TZVP basis set was used on all atoms [58]. The (napthyl) $\mathrm{MgX}$ molecules were optimized under $\mathrm{C}_{\mathrm{s}}$ symmetry, and the (napthyl) ${ }_{2} \mathrm{Mg}$ complexes were run under $C_{2}$ symmetry. Atomic charges were estimated with the Natural Population Analysis protocol (v 3.1) [59,60].

\section{Conclusions}

Mechanochemically induced Grignard reagent formation by the direct ball milling of magnesium metal and an organohalogen $(\mathrm{X}=\mathrm{Cl}, \mathrm{Br})$ has previously been demonstrated to provide products and yields comparable to those obtained in solution reactions [26]. Extension of this technique to fluoronapthalenes has now been shown to induce activation of the C-F bond as well, although yields of, e.g., homocoupled naphthalenes under the conditions used here are low (ca. 20\%). Density functional theory calculations indicate that charges on the $\alpha$-carbon in the naphthalenes are similar in all cases. Thus, although it is clear that activation of the C-F bond of the fluoronapthalenes has occurred, whether a (napthyl) $\mathrm{MgF}$ or a (napthyl) ${ }_{2} \mathrm{Mg}$ species is involved in the coupling reactions is uncertain. Mechanochemical promotion of Grignard reagents offers many other variables in the search for improved conditions (e.g., magnesium source, composition of the grinding balls, type of milling apparatus, temperature of the milling, etc.), and thus it is likely that further optimization of reaction conditions is possible.

Supplementary Materials: The following are available online at http://www.mdpi.com/1420-3049/25/3/570/ s1: General procedures and specific details for carbonyl addition reactions, and coordinates of geometryoptimized structures.

Author Contributions: I.R.S. and T.P.H. were jointly responsible for conceptualization, methodology, and reviewing and editing the manuscript. I.R.S. was responsible for experimental measurements. T.P.H. was responsible for computations, project supervision, and funding acquisition. All authors have read and agreed to the published version of the manuscript. 
Funding: This research was funded by the National Science Foundation, grant number CHE-1665327, and by the American Chemical Society-Petroleum Research Fund, grant number 56027-ND3.

Conflicts of Interest: The authors declare no conflict of interest.

\section{References and Notes}

1. Silverman, G.S.; Rakita, P.E. Handbook of Grignard Reagents; Marcel Dekker, Inc.: New York, NY, USA, 1996.

2. Richey, H.G., Jr. Grignard Reagents: New Developments; J. Wiley and Sons., Ltd.: Chicester, UK, 2000.

3. Ziegler, D.S.; Wei, B.; Knochel, P. Improving the Halogen-Magnesium Exchange by using New Turbo-Grignard Reagents. Chem.-Eur. J. 2019, 25, 2695-2703. [CrossRef] [PubMed]

4. Beillard, A.; Bantreil, X.; Métro, T.-X.; Martinez, J.; Lamaty, F. Alternative Technologies That Facilitate Access to Discrete Metal Complexes. Chem. Rev. 2019, 119, 7529-7609. [CrossRef] [PubMed]

5. Horst, C.; Chen, Y.S.; Kunz, U.; Hoffmann, U. Design, modeling and performance of a novel sonochemical reactor for heterogeneous reactions. Chem. Eng. Sci. 1996, 51, 1837-1846. [CrossRef]

6. Tuulmets, A.; Panov, D. Solvation effects in partially solvated Grignard reagents. J. Organomet. Chem. 1999, 575, 182-186. [CrossRef]

7. Baig, R.B.N.; Varma, R.S. Alternative energy input: Mechanochemical, microwave and ultrasound-assisted organic synthesis. Chem. Soc. Rev. 2012, 41, 1559-1584. [CrossRef] [PubMed]

8. Rieke, R.D.; Hudnall, P.M. Activated Metals. I. Preparation of Highly Reactive Magnesium Metal. J. Am. Chem. Soc. 1972, 94, 7178-7179. [CrossRef]

9. Rieke, R.D.; Li, P.T.-J.; Burns, T.P.; Uhm, S.T. Preparation of highly reactive metal powders. New procedure for the preparation of highly reactive zinc and magnesium metal powders. J. Org. Chem. 1981, 46, 4323-4324. [CrossRef]

10. Rieke, R.D.; Burns, T.P.; Wehmeyer, R.M.; Kahn, B.E. Preparation of Highly Reactive Metal Powders: Some of Their Uses in Organic and Organometallic Synthesis. ACS Symp. Ser. 1987, 333, 223-245.

11. Burns, T.P.; Rieke, R.D. Highly reactive magnesium and its application to organic syntheses. J. Org. Chem. 1987, 52, 3674-3680. [CrossRef]

12. Rieke, R.D. Preparation of Organometallic Compounds from Highly Reactive Metal Powders. Science 1989, 246, 1260-1264. [CrossRef]

13. Rieke, R.D.; Hanson, M.V. New organometallic reagents using highly reactive metals. Tetrahedron 1997, 53, 1925-1956. [CrossRef]

14. Rieke, R.D. Chemical Synthesis Using Highly Reactive Metals; John Wiley: Hobocken, NJ, USA, 2017; p. 480.

15. James, S.L.; Adams, C.J.; Bolm, C.; Braga, D.; Collier, P.; Friščić, T.; Grepioni, F.; Harris, K.D.M.; Hyett, G.; Jones, W.; et al. Mechanochemistry: Opportunities for new and cleaner synthesis. Chem. Soc. Rev. 2012, 41, 413-447. [CrossRef] [PubMed]

16. Rightmire, N.R.; Hanusa, T.P. Advances in Organometallic Synthesis with Mechanochemical Methods. Dalton Trans. 2016, 45, 2352-2362. [CrossRef] [PubMed]

17. Do, J.-L.; Friščić, T. Chemistry 2.0: Developing a New, Solvent-Free System of Chemical Synthesis Based on Mechanochemistry. Synlett 2017, 28, 2066-2092. [CrossRef]

18. Howard, J.L.; Cao, Q.; Browne, D.L. Mechanochemistry as an emerging tool for molecular synthesis: What can it offer? Chem. Sci. 2018, 9, 3080-3094. [CrossRef]

19. Tan, D.; García, F. Main group mechanochemistry: From curiosity to established protocols. Chem. Soc. Rev. 2019, 48, 2274-2292. [CrossRef]

20. Friščić, T.; Mottillo, C.; Titi, H.M. Mechanochemistry for Synthesis. Angew. Chem. Int. Ed. 2020, 59, 1018-1029. [CrossRef]

21. Veit, M.; Hoffmann, U. Reaction mill for liquid/solid conversions to Grignard compounds. Chem. Ing. Tech. 1996, 68, 1279-1282. [CrossRef]

22. Waddell, D.C.; Clark, T.D.; Mack, J. Conducting moisture sensitive reactions under mechanochemical conditions. Tetrahedron Lett. 2012, 53, 4510-4513. [CrossRef]

23. Birke, V.; Schutt, C.; Burmeier, H.; Ruck, W. Defined Mechanochemical Reductive Dechlorination of 1,3,5-Trichlorobenzene at Room Temperature in a Ball Mill. Fresenius Environ. Bull. 2011, 20, 2794-2805.

24. Rowlands, S.A.; Hall, A.K.; McCormick, P.G.; Street, R.; Hart, R.J.; Ebell, G.F.; Donecker, P. Destruction of toxic materials. Nature 1994, 367, 223. [CrossRef] 
25. Birke, V.; Schütt, C.; Ruck, W.K.L. Small Particle Size Magnesium in One-pot Grignard-Zerewitinoff-like Reactions Under Mechanochemical Conditions: On the Kinetics of Reductive Dechlorination of Persistent Organic Pollutants (POPs). In Environmental Applications of Nanoscale and Microscale Reactive Metal Particles; American Chemical Society: Washington, DC, USA, 2009; Volume 1027, pp. 39-54.

26. Harrowfield, J.M.; Hart, R.J.; Whitaker, C.R. Magnesium and aromatics: Mechanically-induced Grignard and McMurry reactions. Aust. J. Chem. 2001, 54, 423-425. [CrossRef]

27. Kaupp, G. Mechanochemistry: The varied applications of mechanical bond-breaking. CrystEngComm 2009, 11, 388-403. [CrossRef]

28. Huheey, J.E.; Keiter, E.A.; Keiter, R.L. Inorg. Chem.: Principles of Structure and Reactivity, 4th ed.; Harper Collins: New York, NY, USA, 1993; p. A-30.

29. Ashby, E.C.; Al-Fekri, D.M. The reaction of benzotrihalides and benzal halides with magnesium. Synthetic and mechanistic studies. J. Organomet. Chem. 1990, 390, 275-292. [CrossRef]

30. Swarts, F. Some aliphatic fluorides. Bull. Soc. Chim. Belg. 1921, 30, 302-305.

31. Respess, W.L.; Ward, J.P.; Tamborski, C. The preparation of a Grignard reagent from hexafluorobenzene by the entrainment technique. J. Organomet. Chem. 1969, 19, 191-195. [CrossRef]

32. Ashby, E.C.; Nackashi, J. The preparation of organomagnesium fluorides by organometallic exchange reactions. J. Organomet. Chem. 1974, 72, 11-20. [CrossRef]

33. Paterová, J.; Skalický, M.; Rybáčková, M.; Kvíčalová, M.; Cvačka, J.; Kvíčala, J. Synthesis of 2-(perfluoroalkyl) ethyl potassium sulfates based on perfluorinated Grignard reagents. J. Fluorine Chem. 2010, 131, 1338-1343. [CrossRef]

34. Respess, W.L.; Tamborski, C. A new synthesis of perfluoroaromatic Grignard reagents. J. Organometal. Chem. 1969, 18, 263-274. [CrossRef]

35. Beck, C.M.; Park, Y.-J.; Crabtree, R.H. Direct conversion of perfluoroalkanes and perfluoroarenes to perfluoro Grignard reagents. Chem. Commun. 1998, 693-694. [CrossRef]

36. Rieke, R.D. Preparation of highly reactive metal powders and their use in organic and organometallic synthesis. Acc. Chem. Res. 1977, 10, 301-306. [CrossRef]

37. Subsequent improvements in the process, including the addition of KI as a promoter, improved yields substantially, and $p$-fluorotoluene was found to produce the corresponding benzoic acid in $69 \%$ yield; fluorooctane yielded $89 \%$ of the carboxylic acid. See Ref. 36.

38. Bare, W.D.; Andrews, L. Formation of Grignard Species from the Reaction of Methyl Halides with Laser-Ablated Magnesium Atoms. A Matrix Infrared Study of $\mathrm{CH}_{3} \mathrm{MgF}, \mathrm{CH}_{3} \mathrm{MgCl}, \mathrm{CH}_{3} \mathrm{MgBr}$, and $\mathrm{CH}_{3}$ MgI. J. Am. Chem. Soc. 1998, 120, 7293-7301. [CrossRef]

39. Tjurina, L.A.; Smirnov, V.V.; Barkovskii, G.B.; Nikolaev, E.N.; Esipov, S.E.; Beletskaya, I.P. Cluster Grignard Reagents. Organometallics 2001, 20, 2449-2450. [CrossRef]

40. Tjurina, L.A.; Smirnov, V.V.; Potapov, D.A.; Nikolaev, S.A.; Esipov, S.E.; Beletskaya, I.P. Synthesis of Cluster Alkyl and Aryl Grignard Reagents in Solution. Organometallics 2004, 23, 1349-1351. [CrossRef]

41. Green, S.P.; Jones, C.; Stasch, A. Stable Magnesium(I) Compounds with Mg-Mg Bonds. Science 2007, 318, 1754-1757. [CrossRef]

42. Bonyhady, S.J.; Jones, C.; Nembenna, S.; Stasch, A.; Edwards, A.J.; McIntyre, G.J. $\beta$-Diketiminate-Stabilized Magnesium(I) Dimers and Magnesium(II) Hydride Complexes: Synthesis, Characterization, Adduct Formation, and Reactivity Studies. Chem.-Eur. J. 2010, 16, 938-955. [CrossRef]

43. Bakewell, C.; White, A.J.P.; Crimmin, M.R. Addition of Carbon-Fluorine Bonds to a Mg(I)-Mg(I) Bond: An Equivalent of Grignard Formation in Solution. J. Am. Chem. Soc. 2016, 138, 12763-12766. [CrossRef]

44. Nagano, T.; Hayashi, T. Iron-Catalyzed Oxidative Homo-Coupling of Aryl Grignard Reagents. Org. Lett. 2005, 7, 491-493. [CrossRef]

45. Other potential coupling reagents were tried ( $\mathrm{Fe}(\mathrm{acac})_{3}, \mathrm{MnCl}_{2}$, and 3,3',5,5'-tetra-t-butyl-diphenoquinone), but none were as effective as $\mathrm{FeCl}_{3}$. This may be a result of differing optimum coupling conditions in the solid state relative to those in solution.

46. Davies, D.I.; Done, J.N.; Hey, D.H. Aspects of the metallic halide-catalysed reaction of Grignard reagents with organic halides. Part II. Effect of variation in reactants. J. Chem. Soc. C: Organic 1969, 1392-1401. [CrossRef]

47. Shan, N.; Toda, F.; Jones, W. Mechanochemistry and co-crystal formation: Effect of solvent on reaction kinetics. Chem. Commun. 2002, 2372-2373. [CrossRef] 
48. Friščić, T.; Trask, A.V.; Jones, W.; Motherwell, W.D.S. Screening for Inclusion Compounds and Systematic Construction of Three-Component Solids by Liquid-Assisted Grinding. Angew. Chem. Int. Ed. 2006, 45, 7546-7550. [CrossRef] [PubMed]

49. Friščić, T.; Childs, S.L.; Rizvi, S.A.A.; Jones, W. The role of solvent in mechanochemical and sonochemical cocrystal formation: A solubility-based approach for predicting cocrystallisation outcome. CrystEngComm 2009, 11, 418-426. [CrossRef]

50. Bandari, R.; Höche, T.; Prager, A.; Dirnberger, K.; Buchmeiser, M.R. Ring-Opening Metathesis Polymerization Based Pore-Size-Selective Functionalization of Glycidyl Methacrylate Based Monolithic Media: Access to Size-Stable Nanoparticles for Ligand-Free Metal Catalysis. Chem.-Eur. J. 2010, 16, 4650-4658. [CrossRef] [PubMed]

51. Viswanathan, G.S.; Wang, M.; Li, C.-J. A Highly Regioselective Synthesis of Polysubstituted Naphthalene Derivatives through Gallium Trichloride Catalyzed Alkyne-Aldehyde Coupling. Angew. Chem. Int. Ed. 2002, 41, 2138-2141. [CrossRef]

52. Nising, C.F.; Schmid, U.K.; Nieger, M.; Bräse, S. A New Protocol for the One-Pot Synthesis of Symmetrical Biaryls. J. Org. Chem. 2004, 69, 6830-6833. [CrossRef]

53. Cassidei, L.; Sciacovelli, O. Iterative analysis of the $1 \mathrm{H}$ NMR spectra of naphthalene ( $\mathrm{AA}^{\prime} \mathrm{A}^{\prime \prime} \mathrm{A}^{\prime \prime \prime} \mathrm{BB}^{\prime} \mathrm{B}^{\prime \prime}$ $\mathrm{B}^{\prime \prime \prime}$ system) and two of its derivatives. Org. Magn. Reson. 1981, 15, 257-262. [CrossRef]

54. Frisch, M.J.; Trucks, G.W.; Schlegel, H.B.; Scuseria, G.E.; Robb, M.A.; Cheeseman, J.R.; Scalmani, G.; Barone, V.; Petersson, G.A.; Nakatsuji, H.; et al. Gaussian 16 Rev. C.01; Gaussian, Inc.: Wallingford, CT, USA, 2016.

55. Becke, A.D. Density-functional thermochemistry. III. The role of exact exchange. J. Chem. Phys. 1993, 98, 5648-5652. [CrossRef]

56. Grimme, S.; Antony, J.; Ehrlich, S.; Krieg, H. A consistent and accurate ab initio parametrization of density functional dispersion correction (DFT-D) for the 94 elements H-Pu. J. Chem. Phys. 2010, 132, 154104. [CrossRef]

57. Grimme, S.; Ehrlich, S.; Goerigk, L. Effect of the damping function in dispersion corrected density functional theory. J. Comput. Chem. 2011, 32, 1456-1465. [CrossRef]

58. Weigend, F.; Ahlrichs, R. Balanced basis sets of split valence, triple zeta valence and quadruple zeta valence quality for H to Rn: Design and assessment of accuracy. Phys. Chem. Chem. Phys. 2005, 7, 3297-3305. [CrossRef]

59. Reed, A.E.; Weinstock, R.B.; Weinhold, F.J. Natural population analysis. J. Chem. Phys. 1985, 83, 735-746. [CrossRef]

60. Reed, A.E.; Curtiss, L.A.; Weinhold, F. Intermolecular interactions from a natural bond orbital, donor-acceptor viewpoint. Chem. Rev. 1988, 88, 899-926. [CrossRef]

Sample Availability: Samples of the compounds are not available from the authors.

(C) 2020 by the authors. Licensee MDPI, Basel, Switzerland. This article is an open access article distributed under the terms and conditions of the Creative Commons Attribution (CC BY) license (http://creativecommons.org/licenses/by/4.0/). 